\title{
Executive Functions and Attention in Childhood Epilepsies: A Neuropsychological Hallmark of Dysfunction?
}

\author{
Elisa Cainelli ${ }^{1,2, *}$ (1) , Jacopo Favaro ${ }^{2}$, Pietro De Carli ${ }^{1}$, Concetta Luisi ${ }^{2,3}$, Alessandra Simonelli ${ }^{1}$, Marilena Vecchi $^{2}$, \\ Stefano Sartori ${ }^{2}$ and Clementina Boniver ${ }^{2}$ \\ ${ }^{1}$ Department of Developmental Psychology and Socialization, University of Padova, 35100 Padova, Italy \\ ${ }^{2}$ Paediatric Neurology and Neurophysiology Unit, Department of Women's and Children's Health, University Hospital of Padova, 35100 Padova, Italy \\ ${ }^{3}$ Department of Neuroscience, University Hospital of Padova, 35100 Padova, Italy
}

(Received April 1, 2020; Final revision September 16, 2020; Accepted September 22, 2020; First Published Online November 13, 2020)

\begin{abstract}
Objective: Patients with epilepsy are at risk for several lifetime problems, in which neuropsychological impairments may represent an impacting factor. We evaluated the neuropsychological functions in children suffering from three main epilepsy categories. Further, we analyzed the longitudinal evolution of the neuropsychological profile over time.

Methods: Patients undergoing neuropsychological evaluation at our Department from 2012 to 2018 were identified retrospectively. We selected patients aged 6-16 years and with at least two evaluations. Three epilepsy categories were considered: focal/structural, focal self-limited, and idiopathic generalized. Each evaluation included the same structured assessment of main neuropsychological domains. The effect of the epilepsy category, illness duration, seizure status, and medication was computed in multilevel models. Results: We identified 103 patients (focal self-limited $=27$; focal/ structural $=51$; and idiopathic generalized $=25$ ), for 233 evaluations. The majority of deficits were reported in attention and executive functions ( $>30 \%$ of patients); the results were dichotomized to obtain global indexes. Multilevel models showed a trend toward statistical significance of category of epilepsy on the global executive index and of illness duration on global attention index. Illness duration predicted the scores of executive and attention tasks, while category and medication predicted executive task performance. Focal/structural epilepsies mostly affected the executive domain, with deficits persisting over time. By contrast, an ameliorative effect of illness duration for attention was documented in all epilepsies. Conclusions: This study offers lacking information about the evolution of deficits in time, the role of epilepsy category, and possible psychological implications for high-order cognitive skills, central in several social and academic problems.
\end{abstract}

Keywords: Epilepsy, Impairments, Neurocognitive, Focal, Generalized, Self-limited

\section{INTRODUCTION}

Patients with epilepsy are at risk for several problems, which can affect their life quality and social competences more than the seizures themselves.

Among these issues, cognitive and neuropsychological impairments represent a very impacting factor, particularly in those patients who show structural etiology (Rudzinski \& Meador, 2013; Witt \& Helmstaedter, 2012). For example, the reported incidence of cognitive dysfunctions in children with focal cortical dysplasia ranges from 50\% to $80 \%$ (Korman et al., 2013; Krsek et al., 2008). Furthermore, other

*Correspondence and reprint requests to: Elisa Cainelli, Ph.D., Department of Developmental Psychology and Socialization, University of Padova, Via Venezia 8, 35133 Padova, Italy. E-mail: elisa.cainelli@ unipd.it structural epilepsies, such as temporal lobe epilepsy, associated with mesiotemporal sclerosis, have been associated with high rates of cognitive impairments (Allone et al., 2017). Furthermore, recent findings have shown in pediatric temporal lobe epilepsy an association of executive functions with depression (Schraegle, Nussbaum, \& Titus, 2018). However, impairment of overall cognitive function or isolated neuropsychological difficulties, such as visual perception, attention, and memory, have been reported even in self-limited focal epilepsies in childhood, with no MRI evidence of brain lesions, easily controlled seizures, and good prognosis (Deonna et al., 2000; Pal et al., 2016). The risk of both pervasive and specific neuropsychological impairments is also reported in idiopathic generalized epilepsy (Henkin et al., 2005; Loughman, Bowden, \& D'Souza, 2014). In fact, both self-limited focal epilepsies and 
idiopathic generalized epilepsies have a complex and polygenic genetic background that could be in a relationship and in common with cognitive impairment (Lesca et al., 2012; Ratcliffe et al., 2020). Finally, the most severe condition is represented by the developmental and epileptic encephalopathies with neonatal to childhood-onset that are associated with drug-resistant epilepsy and significant cognitive impairment.

Among the possible neuropsychological disturbances, executive and attention problems are highly reported and they are a common feature among the different epilepsies types (Conant, Wilfong, Inglese, \& Schwarte, 2010; CulhaneShelburne, Chapieski, Hiscock, \& Glaze, 2002; D'Agati, Cerminara, Casarelli, Pitzianti, \& Curatolo, 2012) (Witt \& Helmstaedter, 2012; for a review, see MacAllister, Vasserman, Rosenthal, \& Sherman, 2014). However, the cause of this association deserves further investigation. Executive functions represent a constellation of cognitive skills that drive goal-oriented behavior and are critical to the ability to adapt to an ever-changing world. Up to $50 \%$ of children with epilepsy demonstrate executive dysfunctions (Campiglia et al., 2014; Høie et al., 2008; Parrish et al., 2007; Slick, Lautzenhiser, Sherman, \& Eyrl, 2006). Deficits can persist or worsen over time (Bailet \& Turk, 2000; Masur et al., 2013; Piccinelli et al., 2010) with impact on academic (Fastenau et al., 2004; Høie et al., 2008) and social functioning (Nassau \& Drotar, 1997). In the same way, attention deficits have been found to have significant implications on children's global functioning in the presence of epilepsy. Interestingly, it has shown that inattention is specifically implicated in academic underachievement (Seidenberg et al., 1988) and that attention appears to be the only variable that predicts academic performance in children with epilepsy among memory abilities, self-esteem, and socioeconomic status and after controlling for intelligence (Williams et al., 2001). ADHD is also overrepresented among children with epilepsy in comparison to the general population (Dunn \& Kronenberger, 2005); furthermore, epileptic patients with ADHD meet the usual criteria for inattentive-type ADHD (Dunn \& Kronenberger, 2005; Gascoigne et al., 2017).

With the aim to provide an overview of neuropsychological impairments in childhood epilepsies, with a particular focus on attention and executive functions, we evaluated the performances of children suffering from the three main categories of epilepsy, such as focal/structural epilepsies, focal self-limited epilepsies, and generalized epilepsies. Further, we analyzed the longitudinal evolution of the neuropsychological profile in these three groups of patients.

\section{METHODS}

\section{Participant and Eligibility Criteria}

We retrospectively identified all patients undergoing neuropsychological evaluation at the Pediatric Neurology and Neurophysiology Unit of the Department of Women's and
Children's Health, University Hospital of Padua (Italy) between September 2012 and February 2018. Among all the identified patients, we considered only those with complete and standardized evaluations. Subsequently, we selected those patients with at least two subsequent neuropsychological assessment. In order to increase the comparability between neuropsychological tests, we selected the patients aged 6 to 16 years.

Children were grouped based on the three following categories: focal/structural epilepsies, so-called focal selflimited, and idiopathic generalized epilepsies (Scheffer et al., 2017). Patients with monogenic or genetic syndromes or with not well-defined etiology were excluded.

The authors assert that all procedures contributing to this work comply with the ethical standards of the relevant national and institutional committees on human experimentation and with the Helsinki Declaration of 1975, as revised in 2008 .

\section{Clinical and Neurological Characteristics}

We collected the following demographic data of the sample: gender, handedness, age at diagnosis, and comorbidities.

Patients underwent diagnostic procedures to define the type of epilepsy, etiology, and, when possible, epileptic syndrome, according to the 2017 Position Paper of ILAE Commission for Classification and Terminology (Scheffer et al., 2017).

The diagnostic process included clinical-anamnestic and neurological evaluations, Video-EEG during wakefulness and sleep, long-term EEG monitoring (in cases where routine EEG was not sufficient for classification), high-resolution cerebral MRI, and, when indicated, 18 F-FDG PET-MRI.

Focal epilepsies were defined as structural when clinical or electro-clinical semiology of the seizures was attributable to the structural alterations which were shown on MRI. In structural epilepsies, we also included cases in which, although there was no precise etiological diagnosis (negative MRI or aspecific findings), the electro-clinical data, the monomorphism of the seizures during evolution, the pharmacoresistance/ pharmaco-dependence and, if available, PET-MRI data, oriented toward a structural etiology.

The definition of a specific syndrome is possible only considering the presence of a cluster of features incorporating seizure types, EEG data, neuroimaging, and comorbidities.

Data on seizure status and medication at each evaluation were collected and considered in the analysis. Seizure frequency was evaluated in the 3 months preceding neuropsychological assessment. It was defined as: daily (at least one seizure/day), weekly (at least one seizure/week), monthly (more than one seizure/month), sporadic (one seizure/month or less), as well as seizure-free patients. Medication has scored as follows: no medication, monotherapy, and politherapy. The presence of comorbidities has been evaluated and summarized as follows: no comorbidities, psychopathological comorbidities, and medical comorbidities. 


\section{Neuropsychological Assessment}

For each evaluation, we collected the age of the child and the time elapsed from the diagnosis of epilepsy (expressed in months and defined as "illness duration"). The clinical setting in which neuropsychological assessments were performed is described in the following paragraph.

Children with a new diagnosis of epilepsy are sent to the neuropsychological service for an assessment. This evaluation is not always performed very close to the onset of epilepsy because ours is a tertiary referral hospital, and the diagnosis is often made in other centers. Furthermore, we want to avoid possible interfering effects associated with the diagnostic process. Subsequent evaluations are performed at least a year apart to avoid practice effects. Usually, children with a new onset of epilepsy underwent an initial evaluation and a follow-up; however, if there is a clinical indication, patients may perform multiple evaluations. The clinical indication may refer to trouble not only on cognitive function or academic problems but also on medical or factors associated with epilepsy without apparently cognitive counterpart. A structured neuropsychological evaluation characterizes each assessment carried out by a trained child neuropsychologist (E.C.). The following cognitive domains were assessed: abstract reasoning, using the Raven Colored Matrices (Raven, Raven, \& Court, 1998); language, using the naming test and the semantic verbal fluency test (Bisiacchi, Cendron, Gugliotta, Tressoldi, \& Vio, 2005); memory, using the digit span test and the Corsi block-tapping test, which evaluate short-term verbal and visual-spatial memory, the words list and list recall, which evaluate learning and long-term verbal memory (Bisiacchi et al., 2005), and the backward digit span test, which evaluates working memory (Bisiacchi et al., 2005); attention, using the Bells test (Stoppa \& Biancardi, 1997), which evaluates selective and sustained attention, and the Trial Making Test A (TMT A) (Scarpa et al., 2006), which evaluates scan and search speed; executive functions, using the phonemic verbal fluency test, which evaluates the ability to access the lexicon through a phonemic cue by setting up an adequate verbal search strategy (Bisiacchi et al., 2005); the Frontal Assessment Battery (FAB) (Scarpa et al., 2006), which evaluates frontal lobes functions; the Trial Making Test B (TMT B), which evaluates attention shifting (Scarpa et al., 2006); and visual-motor abilities, using the Rey-Osterrieth Complex Figure Test (Caffarra, Vezzadini, Dieci, Zonato, \& Venneri, 2002), which evaluates praxis and planning abilities.

Description, procedure, and references for all neuropsychological tasks used are reported in the Supplement Table A.

\section{Statistical Analysis}

Scores for the neuropsychological instruments were agecorrected and converted into $z$-scores, equivalent or standard scores, as appropriate, using published normative data. The $z$-scores indicate the deviation from the mean population score, which is set to 0 , standard deviation 1 . A $z$ score of -2 (or less) comprises $2.5 \%$ of the normal distribution and is considered to be significantly lower than average. Equivalent scores are a 5-point scale standardized after adjustment for age and education. An equivalent score of 0 is considered to be significantly lower than average, one a borderline score, and 2-5 average scores. Standard scores indicate the deviation from the mean population score, which is set to 10 , standard deviation 3 . A standard score of 4 (or less) is considered to be significantly lower than average.

We calculated a global index of dysfunctions for executive functions and attention from impairments of single functions: we classified this as a dysfunction if a patient obtained an impaired score on at least two tasks. This methodology provided dichotomous values, and it is useful in order to quantify a range of impairments in a unitary measure.

In order to test the linear effect of illness duration, the child's age at each assessment was computed and used as a predictor (centered and considered as a fixed and random effect) in different multilevel models, in addition to the other target predictor (i.e., epilepsy category) and the control variable (i.e., the medication). Multilevel linear models were implied for phonemic fluency, TMT B, FAB, Bells accuracy, and rapidity. Multilevel logistic models were computed for attention and executive functioning global indexes. Since we were also interested in the moderation of the epilepsy category on the effect of illness duration, we tested two models for each dependent variable: one with the main effects and one with the main effects as well as the interaction effect of illness duration $\times$ diagnosis. Analyses were performed with R-software (R Core Team, 2020), using the lme4 package (Bates, Mächler, Bolker, \& Walker, 2015) for multilevel modeling, the Car package (Fox \& Weisberg, 2011) to obtain Type II Wald chi-square tests. $R^{2}$ calculation is based on Nakagawa, Johnson, \& Schielzeth (2017). In order to interpret the significant interaction effect of diagnosis and illness duration, the library effects (Fox, 2003) were used to represent the results visually, and simple slope analysis was performed utilizing the reghelper package (Hughes, 2017). Finally, we repeated the main analyses controlling the models also for the potentially confounding effect of the seizure status, and results are reported in the supplementary materials.

\section{RESULTS}

The flow chart with the procedure of selection of the final sample is reported in Figure 1.

According to the above-mentioned eligibility criteria, we identified 103 patients (focal self-limited $N=27$; focal/ structural $N=51$; generalized $N=25$ ) and 233 neuropsychological evaluations. Of the self-limited epilepsy group, 19 patients $(70.4 \%)$ had two assessments, 6 (22.2\%) three assessments, and 2 (7.4\%) four assessments. Of the focal/ structural epilepsy group, 40 patients (78.4\%) had two assessments, $10(19.6 \%)$ three assessments, and $1(2 \%)$ had four 


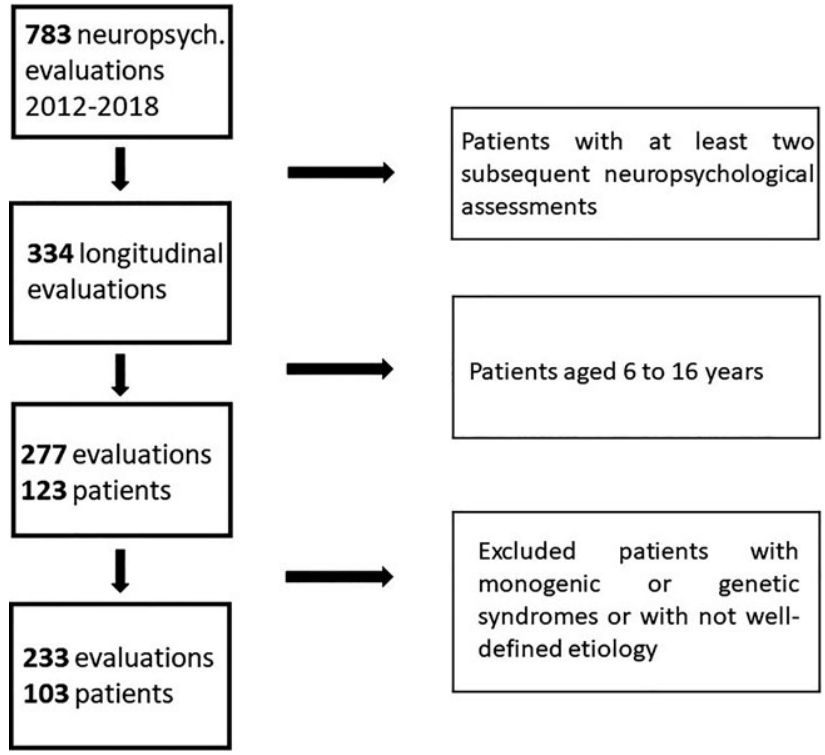

Fig. 1. Flow chart with the procedure of selection of the final sample.

assessments. Of the generalized epilepsy group, 21 patients (84\%) had two assessments, 4 (16\%) three assessments, and none had four assessments.

The percentage of medication used, alone or combined in a polytherapy, respectively, at first and at last assessment, is carbamazepine $(21.9 \%, 18.2 \%)$, valproic acid $(35.4 \%$, $40.9 \%)$, oxcarbazepine $(8.3 \%, 8 \%)$, levetiracetam $(15.6 \%$, $14.8 \%)$, ethosuximide $(9.4 \%, 6.8 \%)$, methylphenidate $(0 \%$, $1.1 \%)$, lacosamide $(1 \%, 2.3 \%)$, topiramate $(1 \%, 0 \%)$, lamotrigine $(4.2 \%, 5.7 \%)$, clobazam $(1 \%, 2.3 \%)$, clonazepam $(1 \%, 0 \%)$, and dintoin $(1 \%, 0 \%)$.

Table 1 reports the demographic data, comorbidities, temporal characteristics of the evaluations, seizure status, and medication at first and last evaluation considered for the three groups.

Within the focal self-limited epilepsy group, we were able to identify an epileptic syndrome in all the cases. Fourteen patients $(51.8 \%)$ were classified as affected by childhood epilepsy with centrotemporal spikes, $9(33.3 \%)$ by Panayiotopoulos syndrome, $3(11.1 \%)$ by childhood occipital epilepsy and only one patient $(3.7 \%)$ was classified as affected by LandauKleffner syndrome.

Within the generalized epilepsy group, we were able to define an epileptic syndrome in 21 cases (84\%). Eight patients (32\%) were classified as affected by childhood absence epilepsy, 5 (20\%) by Epilepsy with myoclonic, atonic seizures, and $4(16 \%)$ by epilepsy with eyelid myoclonias. Juvenile myoclonic epilepsy, juvenile absence epilepsy, epilepsy with generalized tonic-clonic seizures alone and myoclonic epilepsy in infancy were represented by one patient each (4\%)

In order to further characterize the group of patients affected by focal epilepsy of structural etiology, we specify in Table 2 the different types of lesions that we have identified. However, in 15 cases $(29.4 \%)$, the MRI was normal, and in 6 cases $(11.7 \%)$, the neuroimaging data revealed only aspecific structural abnormalities (asymmetry of temporo-mesial structures, or in the organization of sulci and gyri). These patients, as explained in the methods, were classified as focal/structural epilepsies according to a comprehensive evaluation of electro-clinical phenotype, and PET data if available. Among the 30 patients with a defined structural lesion, in 20 cases $(67 \%)$, it was unilateral ( $55 \%$ of lesions localized in the left hemisphere, $45 \%$ of lesions in the right hemisphere). In 10 patients $(33 \%)$, the lesion involved both the cerebral hemispheres. In 17 patients $(57 \%)$, the extension of the structural abnormality was limited to one lobe; frontal lobes were involved in $30.3 \%$ of cases, temporal lobes in $39.3 \%$ of cases, parietal lobes in $24.2 \%$ of cases and occipital lobes in $6 \%$ of cases.

Within the focal/structural epilepsy group, seven patients $(13.7 \%)$ were surgically treated.

The percentage of deficits and mean $z$-scores reported in neuropsychological tasks at the first and last assessment for each group of patients are reported in Tables 3 and 4 .

Results of the multilevel models aimed at testing the effects of illness duration, epilepsy category, and medication on executive tasks are presented in Table 5.

The multilevel logistic regression found no change in time for the global executive index as well as no effect of the medication. Still, a trend toward statistical significance $(p=.06)$ has been shown for the effect of the epilepsy category. No interaction between illness duration and epilepsy category was found. On the contrary, as shown in Figure 2, Phonemic fluency increases over time and its score significantly decreases when the medication increases. Also, the epilepsy categories differ in terms of Phonemic fluency, suggesting that focal self-limited epilepsies are associated with lower fluency, while focal/ structural epilepsies obtain higher scores but lower when compared with generalized epilepsies. No significant interaction between illness duration and epilepsy category was found.

Neither main effects nor interaction effects were found for TMT B, while a significant diagnosis $\times$ time interaction has been found for FAB. Figure 3 shows the effects, and subsequent simple slope analyses show that time has a positive nonsignificant effect on the epilepsy category $=$ focal self-limited $(b=.41, \mathrm{SE}=.30, t=1.38, p>.05$, Cohen's $d=.75)$, a non-significant positive effect on epilepsy category $=$ focal $/$ structural $(b=.04, \mathrm{SE}=.15, t=.30, p>.05$, Cohen's $d=.17)$, and a significant negative effect on epilepsy category $=$ generalized $(b=-.58, \mathrm{SE}=.23, t=-2.40, p<.05$, Cohen's $d=-1.02$ ). In other words, only the patients with generalized epilepsy show a change of FAB over time, independently of the medication used.

The results of the multilevel models aimed at testing the effects of illness duration, epilepsy category, and medication on attention are presented in Table 6.

Regarding the global attention index, the multilevel logistic model shows no significant effect of medication and epilepsy category. Still, a trend toward statistical significance $(p=.07)$ suggests that attention tends to increase over time. No interaction between illness duration and epilepsy category was found. Bells accuracy and rapidity are significantly increased over time, but neither main effects of medication of type of epilepsy nor interaction effects were found. 
Table 1. For each examined epilepsy category, gender, handedness, comorbidities, age at onset, the time elapsed (in months) from the diagnosis to the first and last evaluation, the number of evaluations performed, and the age (in months) at the diagnosis, seizure status, and medication are reported

\begin{tabular}{|c|c|c|c|c|c|}
\hline & Focal self-limited & Focal/Structural & Generalized & $p$-value & Effect size \\
\hline Gender, male, number $(\%)$ & $16(59.3)$ & $29(56.9)$ & $18(72.0)$ & .43 & $V=0.13$ \\
\hline Handedness, right, number $(\%)$ & $24(88.9)$ & $41(80.4)$ & $20(80.0)$ & .06 & $V=0.10$ \\
\hline Comorbidities, number (\%) & & & & .36 & $V=0.12$ \\
\hline No comorbidities & $19(70.4)$ & $35(68.6)$ & $17(68.0)$ & & \\
\hline Psychopathological comorbidities & $5(18.5)$ & 9 (17.6) & $8(32.0)$ & & \\
\hline Medical comorbidities & $3(11.1)$ & $7(13.7)$ & $0(0.0)$ & & \\
\hline Age at onset (months), Mean $\pm S D$ & $68.85 \pm 29.38$ & $79.02 \pm 48.47$ & $70.16 \pm 45.04$ & .54 & $\eta^{2}=0.01$ \\
\hline First evaluation (months), Mean $\pm S D$, range & $30.59 \pm 22.57,0-87$ & $48.9 \pm 49.75,0-182$ & $48.2 \pm 37.04,2-131$ & .15 & $\eta^{2}=0.04$ \\
\hline Last evaluation (months), Mean $\pm S D$, range & $51.89 \pm 29,14-119$ & $68.4 \pm 41.4,8-184$ & $71.4 \pm 40.7,16-182$ & .03 & $\eta^{2}=0.06$ \\
\hline Number of evaluations, Mean $\pm S D$ & $2.37 \pm 0.62$ & $2.24 \pm 0.47$ & $2.16 \pm 0.37$ & .30 & $\eta^{2}=0.02$ \\
\hline Seizure status first evaluation, number (\%) & & & & .02 & $V=0.28$ \\
\hline Seizure-free & $12(44.4)$ & $24(47.1)$ & $11(44.0)$ & & \\
\hline Sporadic & $9(33.3)$ & 9 (17.6) & $2(8.0)$ & & \\
\hline Monthly & $3(11.1)$ & $4(7.8)$ & $1(4.0)$ & & \\
\hline Weekly & $0(0.0)$ & $6(11.8)$ & $1(4.0)$ & & \\
\hline Daily & $3(11.1)$ & $8(15.7)$ & $10(40.0)$ & & \\
\hline Seizure status last evaluation, number (\%) & & & & .13 & $V=0.18$ \\
\hline Seizure-free & $20(74.1)$ & $37(72.5)$ & $17(68.0)$ & & \\
\hline Sporadic & $1(3.7)$ & $4(7.8)$ & $0(0.0)$ & & \\
\hline Monthly & $3(11.1)$ & $4(7.8)$ & $1(4.0)$ & & \\
\hline Weekly & $1(3.7)$ & $2(3.9)$ & $2(8.0)$ & & \\
\hline Daily & $2(7.4)$ & $4(7.8)$ & $5(20.0)$ & & \\
\hline Medication first evaluation, number (\%) & & & & .07 & $V=0.18$ \\
\hline No medication & $13(48.1)$ & $12(23.5)$ & $8(32.0)$ & & \\
\hline Monotherapy & $11(40.7)$ & $29(56.9)$ & $11(44.0)$ & & \\
\hline Politherapy & $3(11.1)$ & $10(19.6)$ & $6(24.0)$ & & \\
\hline Medication last evaluation, number (\%) & & & & .18 & $V=0.22$ \\
\hline No medication & $8(26.9)$ & 9 (17.6) & $9(36.0)$ & & \\
\hline Monotherapy & $17(63.0)$ & $31(60.8)$ & $8(32.0)$ & & \\
\hline Politherapy & $2(7.4)$ & $11(21.6)$ & $8(32.0)$ & & \\
\hline
\end{tabular}

Table 2. Different types of lesions of focal/structural epilepsies

\begin{tabular}{lr}
\hline \hline Type of focal lesion & Ratio in the sample - number $(\%)$ \\
\hline Sequelae of acute brain injuries (hypoxic-ischemic encephalopathy, & $10(19.6)$ \\
$\quad$ drug toxicity, and infections) & $7(13.7)$ \\
Focal cortical dysplasia (FCD) & $5(9.8)$ \\
Brain tumor & $2(3.9)$ \\
Vascular malformation & $2(3.9)$ \\
Polymicrogyria & $1(1.9)$ \\
Focal periventricular nodular heterotopias & $1(1.9)$ \\
Tuberous sclerosis complex (TSC) & $1(1.9)$ \\
Hippocampal sclerosis & $15(29.4)$ \\
MRI-negative & $6(11.7)$ \\
Aspecific structural abnormalities & $2(3.9)$ \\
Focal hypometabolism on 18 F-FDG-PET-MRI & 2 \\
\hline \hline
\end{tabular}

The main analyses were repeated, controlling for the potentially confounding effect of seizure status. Results are presented in Supplement tables (Tables B and C) and show that the associations remain unchanged in terms of effect sizes and statistical significance.

\section{DISCUSSION}

In the present study, we found a high percentage of executive and attention deficits in all three categories of examined patients, namely focal/structural epilepsies, so-called focal self-limited, and idiopathic generalized epilepsies. 
Table 3. Percentage of deficits (scores $<2 S D$ ) obtained by the three group of patients at first and last assessment in neuropsychological tasks

\begin{tabular}{|c|c|c|c|c|c|c|c|}
\hline \multicolumn{2}{|l|}{ Domain } & \multicolumn{2}{|c|}{ Task } & \multicolumn{2}{|c|}{$\%$ deficit first assessment } & \multicolumn{2}{|c|}{$\%$ deficit last assessment } \\
\hline & & Self-limited & Structural & Generalized & Self-limited & Structural & Generalized \\
\hline Reasoning & Raven Matrices & $3 / 27(11 \%)$ & $6 / 51(11 \%)$ & $3 / 25(12 \%)$ & $3 / 27(11 \%)$ & $5 / 51(9 \%)$ & $3 / 25(12 \%)$ \\
\hline \multirow[t]{2}{*}{ Language } & Semantic fluency & $5 / 27(18 \%)$ & $12 / 51(23 \%)$ & $3 / 25(12 \%)$ & $3 / 27(11 \%)$ & $10 / 51(19 \%)$ & $3 / 25(12 \%)$ \\
\hline & Naming & $3 / 27(11 \%)$ & $12 / 51(23 \%)$ & $1 / 24(4 \%)$ & $4 / 26(15 \%)$ & $10 / 51(19 \%)$ & $2 / 24(8 \%)$ \\
\hline \multirow[t]{6}{*}{ Memory } & Digit span forward & $1 / 27(3 \%)$ & $7 / 51(13 \%)$ & $4 / 24(16 \%)$ & $1 / 27(3 \%)$ & $5 / 51(9 \%)$ & $1 / 24(4 \%)$ \\
\hline & Digit span backward & $0 / 21(0 \%)$ & $6 / 46(13 \%)$ & $0 / 22(0 \%)$ & $1 / 24(4 \%)$ & $2 / 50(4 \%)$ & $0 / 24(0 \%)$ \\
\hline & Corsi & $2 / 27(7 \%)$ & $2 / 51(3 \%)$ & $1 / 25(4 \%)$ & $1 / 27(3 \%)$ & $2 / 51(3 \%)$ & $0 / 25(0 \%)$ \\
\hline & Word list & $3 / 26(11 \%)$ & $4 / 50(7 \%)$ & $1 / 24(4 \%)$ & $5 / 27(18 \%)$ & $7 / 51(13 \%)$ & $1 / 24(4 \%)$ \\
\hline & List Recall & $3 / 26(11 \%)$ & $5 / 50(9 \%)$ & $0 / 24(0 \%)$ & $1 / 27(3 \%)$ & $6 / 51(11 \%)$ & $0 / 24(0 \%)$ \\
\hline & Rey Recall & $7 / 25(28 \%)$ & $14 / 41(9 \%)$ & $3 / 20(15 \%)$ & $4 / 22(18 \%)$ & $5 / 43(11 \%)$ & $3 / 20(15 \%)$ \\
\hline \multirow[t]{3}{*}{ Attention } & Bell's speed & $11 / 24(45 \%)$ & $9 / 41(21 \%)$ & $8 / 22(36 \%)$ & $3 / 25(12 \%)$ & $3 / 41(7 \%)$ & $3 / 21(14 \%)$ \\
\hline & Bell's accuracy & $6 / 24(25 \%)$ & $6 / 41(14 \%)$ & $6 / 22(27 \%)$ & $3 / 25(12 \%)$ & $4 / 41(9 \%)$ & $1 / 21(4 \%)$ \\
\hline & TMT A & $4 / 24(16 \%)$ & $6 / 45(13 \%)$ & $2 / 22(9 \%)$ & $3 / 23(13 \%)$ & $3 / 46(6 \%)$ & $2 / 22(9 \%)$ \\
\hline Praxis & Rey Figure A & $7 / 25(28 \%)$ & $10 / 41(24 \%)$ & $2 / 21(9 \%)$ & $5 / 22(22 \%)$ & $8 / 43(18 \%)$ & $2 / 23(8 \%)$ \\
\hline \multirow[t]{3}{*}{ Executive Functions } & Phonemic fluency & $6 / 22(27 \%)$ & 9/47 (19\%) & $2 / 22(9 \%)$ & $4 / 22(18 \%)$ & $8 / 48(16 \%)$ & $3 / 23(13 \%)$ \\
\hline & TMT B & $10 / 20(50 \%)$ & $21 / 42(50 \%)$ & $4 / 18(22 \%)$ & $8 / 19(42 \%)$ & $17 / 44(38 \%)$ & $7 / 20(35 \%)$ \\
\hline & FAB & $3 / 25(12 \%)$ & $12 / 42(28 \%)$ & $3 / 21(14 \%)$ & $4 / 23(17 \%)$ & $8 / 42(19 \%)$ & $6 / 22(27 \%)$ \\
\hline
\end{tabular}

Table 4. Mean $z$-scores ( \pm standard deviations) obtained by the three groups of patients at first and last assessment in neuropsychological tasks

\begin{tabular}{|c|c|c|c|c|c|c|c|}
\hline \multirow[b]{2}{*}{ Domain } & \multirow[b]{2}{*}{ Task } & \multicolumn{3}{|c|}{ First assessment ( $z$-scores) } & \multicolumn{3}{|c|}{ Last assessment ( $z$-scores) } \\
\hline & & Self-limited & Structural & Generalized & Self-limited & Structural & Generalized \\
\hline Reasoning & Raven Matrices & $-.07 \pm 1.2$ & $-.26 \pm 1.09$ & $.60 \pm 1.01$ & $-.05 \pm 1.33$ & $.11 \pm 1.06$ & $-.12 \pm 1.02$ \\
\hline \multirow[t]{2}{*}{ Language } & Semantic fluency & $-.77 \pm 1.03$ & $-.94 \pm .9$ & $-.48 \pm 1.1$ & $-.65 \pm .86$ & $-.91 \pm .85$ & $-.67 \pm .83$ \\
\hline & Naming & $-.41 \pm 1.13$ & $-.90 \pm 1.1$ & $.14 \pm .99$ & $-.52 \pm .99$ & $-.63 \pm 1.20$ & $-.18 \pm .95$ \\
\hline \multirow[t]{6}{*}{ Memory } & Digit span forward & $-5.59 \pm .53$ & $-.77 \pm .82$ & $-.64 \pm .81$ & $-.51 \pm .70$ & $-.71 \pm .84$ & $-.57 \pm .71$ \\
\hline & Digit span backward & $-.18 \pm .76$ & $-.63 \pm .98$ & $-.25 \pm .64$ & $-.29 \pm .72$ & $-.48 \pm .86$ & $-.06 \pm .84$ \\
\hline & Corsi & $-.09 \pm .97$ & $-.16 \pm 1.15$ & $-.07 \pm .91$ & $-.05 \pm .99$ & $.23 \pm 1.10$ & $-.15 \pm .83$ \\
\hline & Word list & $-.31 \pm 1.04$ & $-.33 \pm 1.01$ & $.01 \pm .84$ & $-.37 \pm 1.23$ & $-.10 \pm 1.22$ & $.36 \pm .85$ \\
\hline & List Recall & $.14 \pm 1.17$ & $-.19 \pm 1.02$ & $.50 \pm .83$ & $.18 \pm 1.17$ & $-.14 \pm 1.12$ & $.44 \pm .69$ \\
\hline & Rey Recall & $-.45 \pm 1.33$ & $-.24 \pm 1.87$ & $-.41 \pm 1.45$ & $.47 \pm 1.47$ & $.34 \pm 1.58$ & $1.05 \pm 1.46$ \\
\hline \multirow[t]{3}{*}{ Attention } & Bell's speed & $-1.46 \pm 1.31$ & $-.91 \pm 1.45$ & $-1.03 \pm 1.62$ & $-.33 \pm 1.30$ & $-1.12 \pm 1.18$ & $.02 \pm 1.18$ \\
\hline & Bell's accuracy & $-.86+1.14$ & $-.72 \pm 1.24$ & $-.73 \pm 1.40$ & $-.08 \pm 1.22$ & $-.32 \pm 1.25$ & $-.05 \pm 1.03$ \\
\hline & TMT A & $2.5 \pm 1.5$ & $2.7 \pm 1.24$ & $2.5 \pm 1.26$ & $2.59 \pm 1.37$ & $2.57 \pm 1.01$ & $2.83 \pm 1.19$ \\
\hline Praxis & Rey Figure A & $-.43 \pm 1.54$ & $-.02 \pm 1.67$ & $.01 \pm 1.38$ & $-.07 \pm 1.67$ & $.29 \pm 1.75$ & $.18 \pm 1.22$ \\
\hline \multirow[t]{3}{*}{ Executive Functions } & Phonemic fluency & $-.99 \pm 1.20$ & $-.86 \pm 1.02$ & $-.40 \pm .84$ & $-.77 \pm .96$ & $-.73 \pm .96$ & $-.60 \pm .86$ \\
\hline & TMT B & $1.36 \pm 1.57$ & $1.76 \pm 1.77$ & $2.0 \pm 1.41$ & $1.71 \pm 1.53$ & $1.69 \pm 1.60$ & $1.47 \pm 1.34$ \\
\hline & FAB & $1.86 \pm 1.17$ & $1.95 \pm 1.63$ & $2.14 \pm 1.31$ & $2.04 \pm 1.26$ & $2.14 \pm 1.26$ & $1.91 \pm 1.54$ \\
\hline
\end{tabular}

Interestingly, by considering executive dysfunctions, patients with focal/structural epilepsies were the most affected independently of localization of the epileptogenic zone (the group contains several different localizations) and the deficit appeared to be persistent over time. By contrast, we did not find significant differences in frequency of attention impairments between the three groups of patients and an ameliorative effect of illness duration was documented in all the patients: at the last evaluation, attention abilities appeared to get better, independently of the epilepsy category.

\section{Existing Literature}

The finding of a high percentage of executive deficits in our cohort is consistent with the previous literature (Kavanaugh, Scarborough, \& Salorio, 2015; Schraegle \& Titus, 2016). Impairments have been reported among a broad variety of seizure types and etiologies (Parrish et al., 2007; Hermann, Seidenberg, \& Jones, 2008) and have been documented even at the onset of epilepsy (Filippini et al., 2016; Parrish et al., 2007). However, empirical studies that directly compare 
cognitive functioning in children with different epileptic syndromes are very scarce. The majority of studies focused on risk factors, such as medication or seizure frequency, and often based on a retrospective evaluation of nationwide registries. However, some remarkable works have been conducted cross-syndrome comparisons. Fastenau et al. (2009) compared several types of epilepsy, both generalized and "localization-related," with controls sibling. They found that children with symptomatic/cryptogenic etiology performed worse than those with idiopathic etiology on verbal memory and learning. For attention/executive/construction, both localization-related cryptogenic and generalized idiopathic absence groups scored lower than siblings. Another remarkable study is that of Hermann et al. (2008), who searched for cognitive phenotypes in children with new-onset focal and generalized idiopathic epilepsies. Confirmatory factor analysis identified five cognitive factors (verbal, perceptual, speed, attention, and executive), and latent class analysis identified three clusters of participants with epilepsy: (1) average and similar to controls, (2) mild impairment across multiple cognitive domains, and (3) impairment across all domains with severe attentional impairment. A subsequent effort of the same group investigated the neuropsychological profile of children who have new-/recent-onset idiopathic generalized epilepsy and idiopathic localization-related (Jackson et al., 2013). They found considerable cognitive abnormality at baseline, including patterns of shared abnormalities across syndromes (e.g., psychomotor slowing) as well as unique syndrome-specific cognitive effects (e.g., executive function in idiopathic generalized epilepsy and language/verbal memory in idiopathic localization-related epilepsy). Academic difficulties are evident in approximately 50\% of the children with epilepsy, affecting all syndrome groups to an equal degree. Lopes and colleagues examined the IQ (Lopes et al., 2013) and memory abilities (Lopes, Monteiro, Fonseca, Robalo, \& Simões, 2014) in three common epilepsy syndromes (frontal lobe epilepsy, childhood absence epilepsy, and benign epilepsy with centrotemporal spikes). They showed that frontal lobe epilepsy has lower intelligence and memory scores. Also, they showed that type of epilepsy and duration of epilepsy were the best indicators of intellectual functioning and memory problems. Literature reported other interesting examples of syndromes comparisons (Cheng et al., 2017; Culhane-Shelburne et al., 2002; Law, Smith, \& Widjaja, 2018; Nolan et al., 2004; Riccio, Pliego, Cohen, \& Park, 2015).

\section{Discussion of Our Results on Executive Functions}

Although executive problems were overrepresented in each group, our study showed that executive functions were strongly and pervasively affected in focal/structural epilepsies. This result is particularly interesting if we consider that this group comprises patients with different structural abnormalities and localizations of the seizure focus. Executive dysfunctions were originally described on the basis of patterns of 


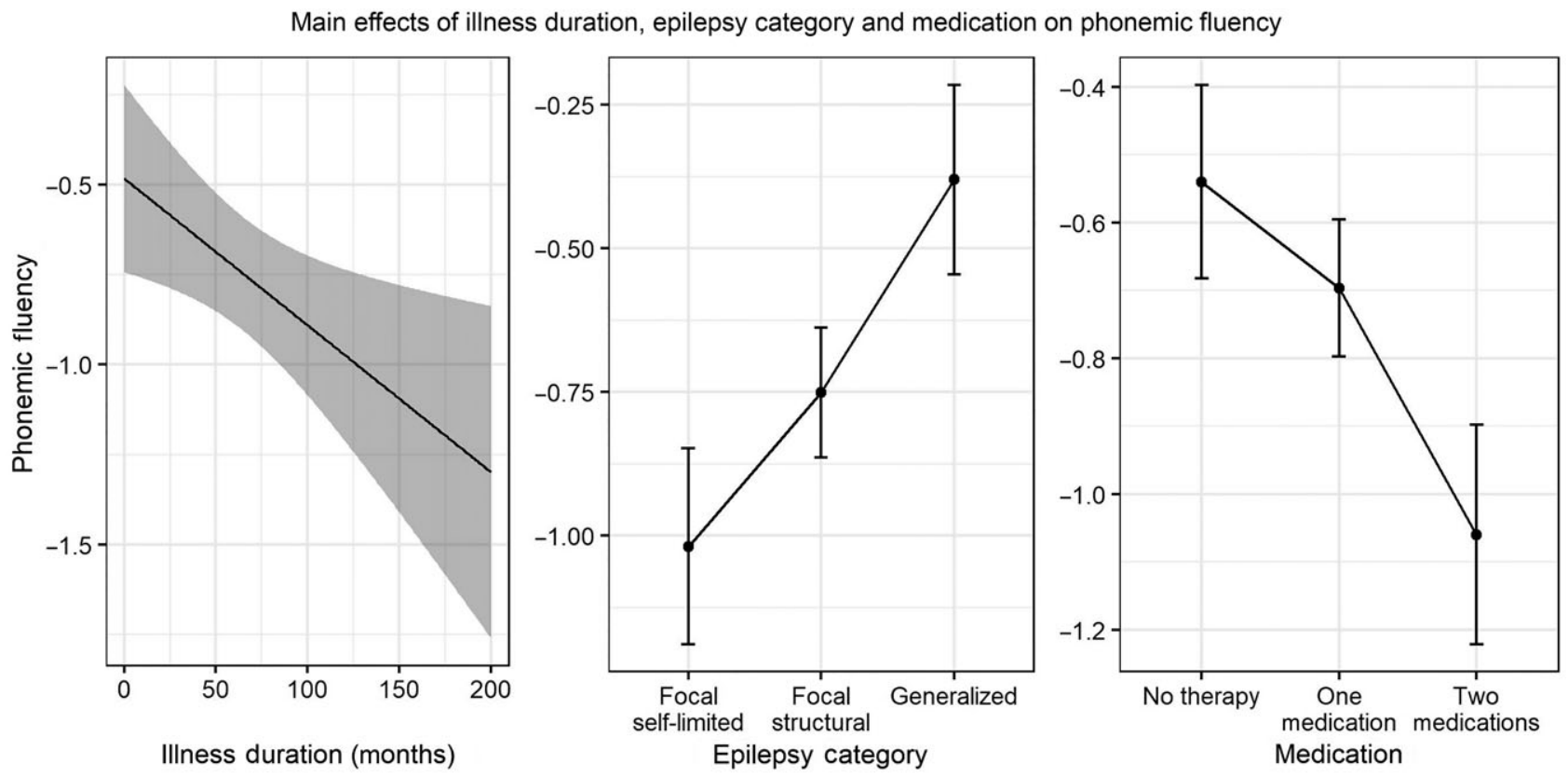

Fig. 2. Main effects of illness duration, epilepsy category, and medication on phonemic fluency.

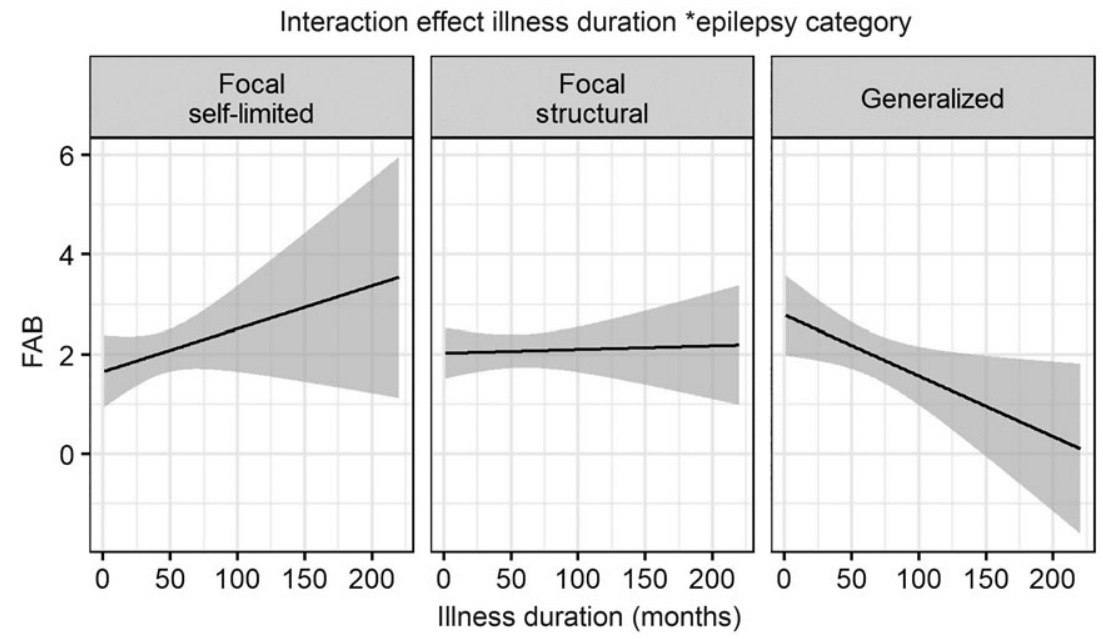

Fig. 3. Interaction effect of illness duration and epilepsy category on FAB.

deficits observed in patients with frontal lobe lesions (Stuss \& Benson, 1984; Stuss, 2011; Rabinovici, Stephens, \& Possin, 2015). Our observations are coherent with recent acquisitions, according to whose executive function depends on distributed neural networks that not only involve the prefrontal cortex prominently but also include parietal cortex, basal ganglia, thalamus, cerebellum, and white matter (Cainelli, Mioni, Boniver, Bisiacchi, \& Vecchi, 2019; Cainelli, Arrigoni, \& Vedovelli, 2020; Collette et al., 2005; Monchi et al., 2006; Rabinovici et al., 2015). It has also been shown in other pathological conditions (Cainelli, Nosadini, Sartori, \& Suppiej, 2019). Even if specific effects on executive function may be more likely with seizures originating from the frontal lobe, focal seizures arising from other lobes may result in secondary impairments (Guimarães et al., 2007; Rzezak et al., 2007), determining interferences in the distributed neural networks underlying executive functions (Pereira et al., 2010; Tracy et al., 2014; Vlooswijk et al., 2011). Interestingly, numerous functional imaging studies in patients with temporal lobe epilepsy have demonstrated altered connectivity in the default mode networks as a probable consequence of disrupted networks in the frontal lobe (Liao et al., 2010; Lin, Riley, Juranek, \& Cramer, 2008; Riederer et al., 2008; Vlooswijk et al., 2011; Waites et al., 2006).

In our patients with focal/structural epilepsies, executive function impairments were more frequent than in patients affected by focal and generalized epilepsies without structural damage. This suggests that the presence of a structural alteration may determine a more pervasive and persistent 
Table 6. Results of the regression analyses on the global attention index and the relative subscales

\begin{tabular}{|c|c|c|c|c|c|c|c|c|c|c|c|c|}
\hline & \multicolumn{4}{|c|}{ Global attention index $(n=103)$} & \multicolumn{4}{|c|}{ Bells accuracy $(n=89)$} & \multicolumn{4}{|c|}{ Bells rapidity $(n=89)$} \\
\hline & \multicolumn{2}{|c|}{ Model 1} & \multicolumn{2}{|c|}{ Model 2} & \multicolumn{2}{|c|}{ Model 1} & \multicolumn{2}{|l|}{ Model 2} & \multicolumn{2}{|c|}{ Model 1} & \multicolumn{2}{|c|}{ Model 2} \\
\hline & $X^{2}$ & $\overline{\Omega^{2}}$ & $X^{2}$ & $\overline{\Omega^{2}}$ & $X^{2}$ & $\Omega^{2}$ & $X^{2}$ & $\overline{\Omega^{2}}$ & $X^{2}$ & $\overline{\Omega^{2}}$ & $X^{2}$ & $\Omega^{2}$ \\
\hline Illness duration & $3.22 \dagger$ & .04 & 1.69 & .04 & $18.86^{* * *}$ & .16 & $19.81 * * *$ & .16 & $7.12 * *$ & .05 & $7.13 * *$ & .05 \\
\hline Medication & 1.39 & .00 & 2.73 & .01 & .55 & .00 & .54 & .00 & .14 & -.01 & .13 & -.01 \\
\hline Epilepsy category & 2.88 & .01 & 1.98 & .00 & 3.75 & .02 & 4.28 & .02 & 1.30 & .00 & 1.48 & .00 \\
\hline Duration $\times$ category & & & 3.47 & .01 & & & 3.31 & .02 & & & 1.35 & .00 \\
\hline Df & 9 & & 11 & & 10.00 & & 12.00 & & 10.00 & & 12.00 & \\
\hline LogLik. & -116.79 & & -114.65 & & -290.53 & & -289.06 & & -277.70 & & -277.29 & \\
\hline Con. $R^{2}$ & .12 & & .15 & & .13 & & .15 & & .06 & & .07 & \\
\hline Marginal $R^{2}$ & .27 & & .30 & & .64 & & .66 & & .46 & & .48 & \\
\hline AIC & 251.57 & & 251.29 & & 581.06 & & 578.13 & & 555.40 & & 554.59 & \\
\hline Model comp & $X^{2}(2$ & $=2.2$ & $4, p=.33$ & & $X^{2}($ & $=3.3$ & $38, p=.18$ & & & 2) $=1$ & $2, p=.49$ & \\
\hline
\end{tabular}

$\dagger p=.070 ; * p<.05 ; * * p<.01 ; * * * p<.001$.

disruption of diffuse cerebral networks compared to other types of non-lesional epilepsies, including the so-called system epilepsies (Avanzini et al., 2012). Interestingly, Rzezak and colleagues already showed that symptomatic epilepsy might determine worse executive performances compared to the so-called cryptogenic epilepsy (Rzezak et al., 2007).

\section{Discussion of Our Results on Attention}

Attention involves several different components and partially overlap with executive functions; previous studies showed that children with epilepsy exhibit a wide range of attention difficulties (D'Alessandro et al., 1990; Gascoigne et al., 2017; SemrudClikeman \& Wical, 1999) and a high percentage of inattentivetype ADHD (Dunn \& Kronenberger, 2005; Gascoigne et al., 2017). However, a cross-sectional design (e.g., Cnaan et al., 2017; D’Alessandro et al., 1990; Deonna et al., 2000; Fonseca Wald et al., 2019; Masur et al., 2013; Shinnar et al., 2017), short follow-up periods and a lack of proper age bias correction (Cnaan et al., 2017; Glauser et al., 2010; Masur et al., 2013; Shinnar et al., 2017) are significant limitations of these studies, making further confirmation necessary. In this regard, our paper based on well-defined eligibility criteria, comparable protocols, and an extended follow-up - confirmed this observation, showing a high percentage of attention deficits without significant differences in frequency between the three groups of examined patients in our cohort. Moreover, an ameliorative effect of time was documented in all the patients independent of the epilepsy category after a consistent longitudinal followup, similar to what was previously observed by Fonseca Wald et al. (2019) in children with absent epilepsy after a follow-up time of more than 12 months, in both children with and without seizure freedom.

The link between attention function and epilepsy is complex; performance in attention skills may be affected by different factors, mainly by neurologic factors, such as ictal and interictal epileptiform activity (Marston, Besag, Binnie, \& Fowler, 1993) and antiepileptic drugs (Loring \& Meador, 2004; Schmitz, 2006). Interestingly, the favorable course of attention displayed in our work is mainly due to the fact that the trend has resulted in being independent of the antiepileptic treatment. Conversely, the potential link between other clinical, neurophysiologic, environmental, and psychological variables has not been explored in our work due to the size of the sample, representing a limitation in our study.

The evolution in time of the attention performance is intriguing and not easy to interpret. The phenomenon is a cross-disease characteristic and did not appear to associate with other clinical variables, such as medication and seizure status. Therefore, we are tempted to interpret it as a psychological factor. Attention is strongly associated with psychological functioning and, in particular to anxiety and depression. It is reasonable to suppose that psychological factors might worsen the attention performance close to diagnosis time. This influence could wane over time, contributing at least in part to the improvement course of attention disturbances (Eysenck, Derakshan, Santos, \& Calvo, 2007; Grillon, Robinson, Mathur, \& Ernst, 2016). At a confirmation, it has shown that in children with new/recent-onset idiopathic generalized and with localization-related epilepsies, behavioral problems are present near the time of diagnosis and tend to abate over time (Zhao et al., 2015). Clinicians working with psychiatric patients (in particular with anxiety disorders and depression) refer to the concept of "cognitive bias," a wide range of patterns of dysfunctions - such as attentional bias due to psychological disturbances. The first evaluation in our Department is not usually performed very close to the onset of epilepsy in order to avoid the effects of the distress due to the new diagnosis. The stigma that, unfortunately, still characterizes this condition may cause patients and their families a long period of distress with a negative impact on the initial neuropsychological presentation. In particular, the parental depression and anxiety associated with these levels of stress 
could initiate a dysfunctional cycle where dysfunctional parental involvement worsens the already challenged developmental trajectory of the child (Cottrell \& Khan, 2005; De Carli, Riem Madelon, \& Parolin, 2017; Sacchi et al., 2018).

\section{CONCLUSION}

In conclusion, our results confirmed the high percentage of deficits in executive abilities and attention in epileptic populations found in previous studies. Patients with focal/ structural epilepsies were mostly affected in the executive domain, independent of localization of the seizure focus, and the deficits persisted over time. By contrast, we did not find significant differences between the three groups of patients in the attention domain and an ameliorative effect of illness duration was documented in all patients. Even if similar problems have already been found in previous literature, few studies in the literature compare different epilepsy syndromes; therefore, despite the several limitations of this study, we add new information about the role of etiology and the evolution of deficits in time. Furthermore, we suggested a possible influence of psychological factors, as shown in other social and academic problems. Executive functions and attention have been shown to play a pivotal role in supporting other neuropsychological functions that may be impaired among patients with pediatric epilepsy (Black et al., 2019). They are strong predictors of adaptive functioning within this population (Culhane-Shelburne et al., 2002). Weak executive skills and attention also predict psychiatric comorbidity and behavioral problems among children with epilepsy (Alfstad et al., 2016; Baum et al., 2010) and have consistently been associated with decreased quality of life among pediatric patients (Love et al., 2016; Schraegle \& Titus, 2016; Sherman, Slick, \& Eyrl, 2006). Interestingly, it has shown that training based on executive functions may improve the quality of life of children with epilepsy (Schraegle \& Titus, 2016). Thus, they remain an essential target for evaluation and the implementation of prompt rehabilitative intervention. Future research might explore the efficacy of an integrative intervention program, which takes care of both the cognitive and the psychological aspects, and their synergistic action.

\section{ACKNOWLEDGMENTS}

This research did not receive any specific grant from funding agencies in the public, commercial, or not-for-profit sectors. The authors assert that all procedures contributing to this work comply with the ethical standards of the relevant national and institutional committees on human experimentation and with the Helsinki Declaration of 1975 , as revised in 2008 .

\section{CONFLICT OF INTEREST}

The authors have nothing to disclose.

\section{SUPPLEMENTARY MATERIAL}

To view supplementary material for this article, please visit https://doi.org/10.1017/S1355617720001125

\section{References}

Alfstad, K., Torgersen, H., Van Roy, B., Hessen, E., Hansen, B.H., Henning, O., ... Lossius, M.I. (2016). Psychiatric comorbidity in children and youth with epilepsy: An association with executive dysfunction? Epilepsy and Behavior, 56, 88-94. https://doi.org/ 10.1016/j.yebeh.2016.01.007

Allone, C., Lo Buono, V., Corallo, F., Pisani, L.R., Pollicino, P., Bramanti, P., \& Marino, S. (2017). Neuroimaging and cognitive functions in temporal lobe epilepsy: A review of the literature. Journal of the Neurological Sciences, 381, 7-15). https://doi. org/10.1016/j.jns.2017.08.007

Avanzini, G., Manganotti, P., Meletti, S., Moshé, S.L., Panzica, F., Wolf, P., \& Capovilla, G. (2012). The system epilepsies: A pathophysiological hypothesis. Epilepsia, 53(5), 771-778. https://doi. org/10.1111/j.1528-1167.2012.03462.x

Bailet, L.L. \& Turk, W.R. (2000). The impact of childhood epilepsy on neurocognitive and behavioral performance: A prospective longitudinal study. Epilepsia, 41(4), 426-431. https://doi.org/ 10.1111/j.1528-1157.2000.tb00184.x

Bates, D., Mächler, M., Bolker, B.M., \& Walker, S.C. (2015). Fitting linear mixed-effects models using lme4. Journal of Statistical Software, 67(1). https://doi.org/10.18637/jss.v067.i01

Baum, K.T., Byars, A.W., deGrauw, T.J., Dunn, D.W., Bates, J.E., Howe, S.R., . . \& Austin, J.K. (2010). The effect of temperament and neuropsychological functioning on behavior problems in children with new-onset seizures. Epilepsy and Behavior, 17(4), 467-473. https://doi.org/10.1016/j.yebeh.2010.01.010

Bisiacchi, P., Cendron, M., Gugliotta, M., Tressoldi, P., \& Vio, C. (2005). BVN. Batteria di Valutazione Neuropsicologica per l'Età Evolutiva. Erickson.

Black, C.L., Shih, S.W., Sepeta, L.N., Facella-Ervolini, J.M., Isquith, P.K., \& Berl, M.M. (2019). Everyday executive function in focal onset pediatric epilepsy on the parent-report BRIEF2. Child Neuropsychology, 25(1), 22-43. https://doi.org/10.1080/ 09297049.2018.1424326

Caffarra, P., Vezzadini, G., Dieci, F., Zonato, F., \& Venneri, A. (2002). Rey-Osterrieth complex figure: Normative values in an Italian population sample. Neurological Sciences, 22(6), 443-447. https://doi.org/10.1007/s100720200003

Cainelli, E., Arrigoni, F., \& Vedovelli, L. (2020). White matter injury and neurodevelopmental disabilities: A cross-disease (dis)connection. Progress in Neurobiology, 193(June), 101845. https://doi.org/10.1016/j.pneurobio.2020.101845

Cainelli, E., Mioni, G., Boniver, C., Bisiacchi, P.S., \& Vecchi, M. (2019). Time perception in childhood absence epilepsy: Findings from a pilot study. Epilepsy and Behavior, 99, 106460. https://doi. org/10.1016/j.yebeh.2019.106460

Cainelli, E., Nosadini, M., Sartori, S., \& Suppiej, A. (2019). Neuropsychological and psychopathological profile of antiNMDAR encephalitis: A possible pathophysiological model for pediatric neuropsychiatric disorders. Archives of Clinical Neuropsychology, 34(8), 1309-1319. https://doi.org/10.1093/ arclin/acy088

Campiglia, M., Seegmuller, C., Le Gall, D., Fournet, N., Roulin, J.L., \& Roy, A. (2014). Assessment of everyday executive 
functioning in children with frontal or temporal epilepsies. Epilepsy and Behavior, 39, 12-20. https://doi.org/10.1016/j. yebeh.2014.07.023

Cheng, D., Yan, X., Gao, Z., Xu, K., Zhou, X., \& Chen, Q. (2017). Common and distinctive patterns of cognitive dysfunction in children with benign epilepsy syndromes. Pediatric Neurology, 72, 36-41.e1. https://doi.org/10.1016/j.pediatrneurol.2016.12.005

Cnaan, A., Shinnar, S., Arya, R., Adamson, P.C., Clark, P.O., Dlugos, D., Hirtz, D.G., Masur, D., \& Glauser, T.A. (2017). Second monotherapy in childhood absence epilepsy. Neurology, 88(2), 182-190. https://doi.org/10.1212/WNL.0000000000003480

Collette, F., Van Der Linden, M., Laureys, S., Delfiore, G., Degueldre, C., Luxen, A., \& Salmon, E. (2005). Exploring the unity and diversity of the neural substrates of executive functioning. Human Brain Mapping, 25(4), 409-423. https://doi.org/10. 1002/hbm.20118

Conant, L.L., Wilfong, A., Inglese, C., \& Schwarte, A. (2010). Dysfunction of executive and related processes in childhood absence epilepsy. Epilepsy and Behavior, 18(4), 414-423. https://doi.org/10.1016/j.yebeh.2010.05.010

Cottrell, L. \& Khan, A. (2005). Impact of childhood epilepsy on maternal sleep and socioemotional functioning. Clinical Pediatrics, 44(7), 613-616. https://doi.org/10.1177/00099 2280504400709

Culhane-Shelburne, K., Chapieski, L., Hiscock, M., \& Glaze, D. (2002). Executive functions in children with frontal and temporal lobe epilepsy. Journal of the International Neuropsychological Society, 8(5), 623-632. https://doi.org/10.1017/S1355617702 801308

D’Agati, E., Cerminara, C., Casarelli, L., Pitzianti, M., \& Curatolo, P. (2012). Attention and executive functions profile in childhood absence epilepsy. Brain and Development, 34(10), 812-817. https://doi.org/10.1016/j.braindev.2012.03.001

D’Alessandro, P., Piccirilli, M., Tiacci, C., Ibba, A., Maiotti, M., Sciarma, T., \& Testa, A. (1990). Neuropsychological features of benign partial epilepsy in children. Italian Journal of Neurological Sciences, 11(3), 265-269. http://www.ncbi.nlm. nih.gov/pubmed/2117599

De Carli, P., Riem Madelon, M.E., \& Parolin, L. (2017). Approachavoidance responses to infant facial expressions in nulliparous women: Associations with early experience and mood induction. Infant Behavior and Development, 49, 104-113. https://doi.org/ 10.1016/j.infbeh.2017.08.005

Deonna, T., Zesiger, P., Davidoff, V., Maeder, M., Mayor, C., \& Roulet, E. (2000). Benign partial epilepsy of childhood: A longitudinal neuropsychological and EEG study of cognitive function. Developmental Medicine and Child Neurology, 42(9), 595-603. https://doi.org/10.1017/S0012162200001122

Dunn, D.W. \& Kronenberger, W.G. (2005). Childhood epilepsy, attention problems, and ADHD: Review and practical considerations. Seminars in Pediatric Neurology, 12(4), 222-228. https:// doi.org/10.1016/j.spen.2005.12.004

Eysenck, M.W., Derakshan, N., Santos, R., \& Calvo, M.G. (2007). Anxiety and cognitive performance: Attentional control theory. Emotion, 7(2), 336-353. https://doi.org/10.1037/1528-3542.7. 2.336

Fastenau, P.S., Johnson, C.S., Perkins, S.M., Byars, A.W., DeGrauw, T.J., Austin, J.K., \& Dunn, D.W. (2009). Neuropsychological status at seizure onset in children: Risk factors for early cognitive deficits. Neurology, 73(7), 526-534. https://doi.org/10.1212/WNL.0b013e3181b23551
Fastenau, P.S., Shen, J., Dunn, D.W., Perkins, S.M., Hermann, B.P., \& Austin, J.K. (2004). Neuropsychological predictors of academic underachievement in pediatric epilepsy: Moderating roles of demographic, seizure, and psychosocial variables. Epilepsia, 45(10), 1261-1272. https://doi.org/10.1111/j.0013-9580.2004. 15204.x

Filippini, M., Ardu, E., Stefanelli, S., Boni, A., Gobbi, G., \& Benso, F. (2016). Neuropsychological profile in new-onset benign epilepsy with centrotemporal spikes (BECTS): Focusing on executive functions. Epilepsy and Behavior, 54, 71-79. https://doi.org/ 10.1016/j.yebeh.2015.11.010

Fonseca Wald, E.L.A., Klinkenberg, S., Voncken, T.P.C., Ebus, S.C.M., Aldenkamp, A.P., Vles, J.S.H., ... Debeij-Van Hall, M.H.J.A. (2019). Cognitive development in absence epilepsy during long-term follow-up. Child Neuropsychology, 25(8), 1003-1021. https://doi.org/10.1080/09297049.2019.1614156

Fox, J. (2003). Effect displays in R for generalised linear models. Journal of Statistical Software, 8(15), 1-27. https://doi.org/10. 18637/jss.v008.i15

Fox, J. \& Weisberg, S. (2011). Package 'car'. Companion to Applied Regression, 2nd ed. Thousand Oaks, CA: Sage (Issue September 2012). Sage Publication. http://socserv.socsci. mcmaster.ca/jfox/Books/Companion

Gascoigne, M.B., Smith, M.L., Barton, B., Webster, R., Gill, D., \& Lah, S. (2017). Attention deficits in children with epilepsy: Preliminary findings. Epilepsy and Behavior, 67, 7-12. https:// doi.org/10.1016/j.yebeh.2016.11.013

Glauser, T.A., Cnaan, A., Shinnar, S., Hirtz, D.G., Dlugos, D., Masur, D., ... Adamson, P.C. (2010). Ethosuximide, valproic acid, and lamotrigine in childhood absence epilepsy. New England Journal of Medicine, 362(9), 790-799. https://doi.org/ 10.1056/NEJMoa0902014

Grillon, C., Robinson, O.J., Mathur, A., \& Ernst, M. (2016). Effect of attention control on sustained attention during induced anxiety. Cognition and Emotion, 30(4), 700-712. https://doi.org/10.1080/ 02699931.2015.1024614

Guimarães, C.A., Li, L.M., Rzezak, P., Fuentes, D., Franzon, R.C., Augusta Montenegro, M., .. . Guerreiro, M.M. (2007). Temporal lobe epilepsy in childhood: Comprehensive neuropsychological assessment. Journal of Child Neurology, 22(7), 836-840. https://doi.org/10.1177/0883073807304701

Henkin, Y., Sadeh, M., Kivity, S., Shabtai, E., Kishon-Rabin, L., \& Gadoth, N. (2005). Cognitive function in idiopathic generalized epilepsy of childhood. Developmental Medicine and Child Neurology, 47(2), 126-132. https://doi.org/10.1017/S0012162205000228

Hermann, B., Seidenberg, M., \& Jones, J. (2008). The neurobehavioural comorbidities of epilepsy: can a natural history be developed? The Lancet Neurology, 7(2), 151-160. https://doi.org/10. 1016/S1474-4422(08)70018-8

Høie, B., Sommerfelt, K., Waaler, P.E., Alsaker, F.D., Skeidsvoll, H., \& Mykletun, A. (2008). The combined burden of cognitive, executive function, and psychosocial problems in children with epilepsy: A population-based study. Developmental Medicine and Child Neurology, 50(7), 530-536. https://doi.org/10.1111/ j.1469-8749.2008.03015.x

Hughes, J. (2017). reghelper: Helper Functions for Regression Analysis (p. 59). https://cran.r-project.org/package=reghelper

Jackson, D.C., Dabbs, K., Walker, N.M., Jones, J.E., Hsu, D.A., Stafstrom, C.E., ... Hermann, B.P. (2013). The neuropsychological and academic substrate of new/recent-onset epilepsies. Journal of Pediatrics, 162(5). https://doi.org/10.1016/j.jpeds.2012.10.046 
Kavanaugh, B.C., Scarborough, V.R., \& Salorio, C.F. (2015). Parent-rated emotional-behavioral and executive functioning in childhood epilepsy. Epilepsy and Behavior, 42, 22-28. https:// doi.org/10.1016/j.yebeh.2014.11.006

Korman, B., Krsek, P., Duchowny, M., Maton, B., Pacheco-Jacome, E., \& Rey, G. (2013). Early seizure onset and dysplastic lesion extent independently disrupt cognitive networks. Neurology, 81(8), 745-751. https://doi.org/10.1212/WNL.0b013e3182a1aa2a

Krsek, P., Maton, B., Korman, B., Pacheco-Jacome, E., Jayakar, P., Dunoyer, C., ... Duchowny, M. (2008). Different features of histopathological subtypes of pediatric focal cortical dysplasia. Annals of Neurology, 63(6), 758-769. https://doi.org/10.1002/ ana.21398

Law, N., Smith, M.L., \& Widjaja, E. (2018). Thalamocortical connections and executive function in pediatric temporal and frontal lobe epilepsy. American Journal of Neuroradiology, 39(8), 1530-1535. https://doi.org/10.3174/ajnr.A5691

Lesca, G., Rudolf, G., Labalme, A., Hirsch, E., Arzimanoglou, A., Genton, P., ... Szepetowski, P. (2012). Epileptic encephalopathies of the Landau-Kleffner and continuous spike and waves during slow-wave sleep types: Genomic dissection makes the link with autism. Epilepsia, 53(9), 1526-1538. https://doi.org/10. 1111/j.1528-1167.2012.03559.x

Liao, W., Zhang, Z., Pan, Z., Mantini, D., Ding, J., Duan, X., ... Chen, H. (2010). Altered functional connectivity and small-world in mesial temporal lobe epilepsy. PLoS ONE, 5(1), e8525. https:// doi.org/10.1371/journal.pone.0008525

Lin, J.J., Riley, J.D., Juranek, J., \& Cramer, S.C. (2008). Vulnerability of the frontal-temporal connections in temporal lobe epilepsy. Epilepsy Research, 82(2-3), 162-170. https://doi.org/ 10.1016/j.eplepsyres.2008.07.020

Lopes, A, Monteiro, J., Fonseca, M., Robalo, C., \& Simões, M. (2014). Memory functioning in children with epilepsy: frontal lobe epilepsy, childhood absence epilepsy, and benign epilepsy with centrotemporal spikes. Behavioural Neurology, 2014. https://doi.org/10.1155/2014/218637

Lopes, AF, Simões, M., Monteiro, J., Fonseca, M., Martins, C., Ventosa, L., ... Robalo, C. (2013). Intellectual functioning in children with epilepsy: Frontal lobe epilepsy, childhood absence epilepsy and benign epilepsy with centro-temporal spikes. Seizure, 22(10), 886-892. https://doi.org/10.1016/j. seizure.2013.08.002

Loring, D.W. \& Meador, K.J. (2004). Cognitive side effects of antiepileptic drugs in children. Neurology, 62(6), 872-877. https:// doi.org/10.1212/01.WNL.0000115653.82763.07

Loughman, A., Bowden, S.C., \& D'Souza, W. (2014). Cognitive functioning in idiopathic generalised epilepsies: A systematic review and meta-analysis. Neuroscience and Biobehavioral Reviews, 43, 20-34. https://doi.org/10.1016/j.neubiorev.2014.02.012

Love, C.E., Webbe, F., Kim, G., Lee, K.H., Westerveld, M., \& Salinas, C.M. (2016). The role of executive functioning in quality of life in pediatric intractable epilepsy. Epilepsy and Behavior, 64, 37-43. https://doi.org/10.1016/j.yebeh.2016.08.018

MacAllister, W.S., Vasserman, M., Rosenthal, J., \& Sherman, E. (2014). Attention and executive functions in children with epilepsy: What, why, and what to do. Applied Neuropsychology: Child, 3(3), 215-225. https://doi.org/10.1080/21622965.2013.839605

Marston, D., Besag, F., Binnie, C.D., \& Fowler, M. (1993). Effects of transitory cognitive impairment on psychosocial functioning of children with epilepsy: a therapeutic trial. Developmental Medicine and Child Neurology, 35(7), 574-581. https://doi.org/ 10.1111/j.1469-8749.1993.tb11694.x
Masur, D., Shinnar, S., Cnaan, A., Shinnar, R.C., Clark, P., Wang, J., ... Glauser, T.A. (2013). Pretreatment cognitive deficits and treatment effects on attention in childhood absence epilepsy. Neurology, 81(18), 1572-1580. https://doi.org/10.1212/WNL. 0b013e3182a9f3ca

Monchi, O., Petrides, M., Strafella, A.P., Worsley, K.J., \& Doyon, J. (2006). Functional role of the basal ganglia in the planning and execution of actions. Annals of Neurology, 59(2), 257-264. https://doi.org/10.1002/ana.20742

Nakagawa, S., Johnson, P.C.D., \& Schielzeth, H. (2017). The coefficient of determination $\mathrm{R}^{2}$ and intra-class correlation coefficient from generalized linear mixed-effects models revisited and expanded. Journal of the Royal Society Interface, 14(134), 20170213. https://doi.org/10.1098/rsif.2017.0213

Nassau, J.H. \& Drotar, D. (1997). Social competence among children with central nervous system-related chronic health conditions: A review. Journal of Pediatric Psychology, 22(6), 771-793. https://doi.org/10.1093/jpepsy/22.6.771

Nolan, M.A., Redoblado, M.A., Lah, S., Sabaz, M., Lawson, J.A., Cunningham, A.M., ... Bye, A.M.E. (2004). Memory function in childhood epilepsy syndromes. Journal of Paediatrics and Child Health, 40(1-2), 20-27. https://doi.org/10.1111/j.1440 1754.2004.00284.x

Pal, D.K., Ferrie, C., Addis, L., Akiyama, T., Capovilla, G., Caraballo, R., ... Koutroumanidis, M. (2016). Idiopathic focal epilepsies: The lost tribe. Epileptic Disorders, 18(3), 252-288. https://doi.org/10.1684/epd.2016.0839

Parrish, J., Geary, E., Jones, J., Seth, R., Hermann, B., \& Seidenberg, M. (2007). Executive functioning in childhood epilepsy: Parentreport and cognitive assessment. Developmental Medicine and Child Neurology, 49(6), 412-416. https://doi.org/10.1111/j. 1469-8749.2007.00412.x

Pereira, F.R.S., Alessio, A., Sercheli, M.S., Pedro, T., Bilevicius, E., Rondina, J.M., .. \& \& Cendes, F. (2010). Asymmetrical hippocampal connectivity in mesial temporal lobe epilepsy: Evidence from resting state fMRI. BMC Neuroscience, 11(1), 66. https:// doi.org/10.1186/1471-2202-11-66

Piccinelli, P., Beghi, E., Borgatti, R., Ferri, M., Giordano, L., Romeo, A., .. . \& Balottin, U. (2010). Neuropsychological and behavioural aspects in children and adolescents with idiopathic epilepsy at diagnosis and after 12 months of treatment. Seizure, 19(9), 540-546. https://doi.org/10.1016/j.seizure.2010.07.014

R Core Team. (2020). The R Project for Statistical Computing (R. D. C. Team (ed.)). R Foundation for Statistical Computing.

Rabinovici, G.D., Stephens, M.L., \& Possin, K.L. (2015). Executive dysfunction. CONTINUUM Lifelong Learning in Neurology, 21(3), 646-659. https://doi.org/10.1212/01.CON.0000466658. 05156.54

Ratcliffe, C., Wandschneider, B., Baxendale, S., Thompson, P., Koepp, M.J., \& Caciagli, L. (2020). Cognitive function in genetic generalized epilepsies: Insights from neuropsychology and neuroimaging. In Frontiers in Neurology (Vol. 11). Frontiers Media S.A. https://doi.org/10.3389/fneur.2020.00144

Raven, J., Raven, J., \& Court, J. (1998). Manual for Raven's Advanced Progressive Matrices (1998 edition). Oxford Psychologists Press. https://vpngate4.hrz.tu-chemnitz.de/+CSCO+1075676763663A2F 2F66707562796E652E7462627479722E7172++/scholar?q=Manu al+for+Raven's + Advanced+Progressive + Matrices $+\% 281998+$ edition $\% 29 \& b \operatorname{tnG}=\& \mathrm{hl}=$ de\&as_sdt $=0 \% 2 \mathrm{C} 5$

Riccio, C.A., Pliego, J.A., Cohen, M.J., \& Park, Y. (2015). Executive function performance for children with epilepsy localized to the frontal or temporal lobes. Applied Neuropsychology: 
Child, 4(4), 277-284. https://doi.org/10.1080/21622965.2014. 923774

Riederer, F., Lanzenberger, R., Kaya, M., Prayer, D., Serles, W., \& Baumgartner, C. (2008). Network atrophy in temporal lobe epilepsy: A voxel-based morphometry study. Neurology, 71(6), 419-425. https://doi.org/10.1212/01.wnl.0000324264.96100.e0

Rudzinski, L.A. \& Meador, K.J. (2013). Epilepsy and neuropsychological comorbidities. CONTINUUM Lifelong Learning in Neurology, 19(3), 682-696). https://doi.org/10.1212/01.CON. 0000431382.06438.cd

Rzezak, P., Fuentes, D., Guimarães, C.A., Thome-Souza, S., Kuczynski, E., Li, L.M., ... Valente, K.D. (2007). Frontal lobe dysfunction in children with temporal lobe epilepsy. Pediatric Neurology, 37(3), 176-185. https://doi.org/10.1016/ j.pediatrneurol.2007.05.009

Sacchi, C., De Carli, P., Vieno, A., Piallini, G., Zoia, S., \& Simonelli, A. (2018). Does infant negative emotionality moderate the effect of maternal depression on motor development? Early Human Development, 119, 56-61. https://doi.org/10.1016/j. earlhumdev.2018.03.006

Scarpa, P., Piazzini, A., Pesenti, G., Brovedani, P., Toraldo, A., Turner, K., ... Bottini, G. (2006). Italian neuropsychological instruments to assess memory, attention and frontal functions for developmental age. Neurological Sciences, 27(6), 381-396. https://doi.org/10.1007/s10072-006-0717-5

Scheffer, I.E., Berkovic, S., Capovilla, G., Connolly, M.B., French, J., Guilhoto, L., ... Zuberi, S.M. (2017). ILAE classification of the epilepsies: Position paper of the ILAE commission for classification and terminology. Epilepsia, 58(4), 512-521. https://doi. org/10.1111/epi.13709

Schmitz, B. (2006). Effects of antiepileptic drugs on mood and behavior. Epilepsia, 47(Suppl. 2), 28-33. https://doi.org/10. 1111/j.1528-1167.2006.00684.x

Schraegle, W.A., Nussbaum, N.L., \& Titus, J.B. (2018). Executive dysfunction and depression in pediatric temporal lobe epilepsy: The contribution of hippocampal sclerosis and psychosocial factors. Journal of the International Neuropsychological Society, 24(6), 606-616. https://doi.org/10.1017/S1355617718000140

Schraegle, W.A. \& Titus, J.B. (2016). Executive function and healthrelated quality of life in pediatric epilepsy. Epilepsy and Behavior, 62, 20-26. https://doi.org/10.1016/j.yebeh.2016.06.006

Seidenberg, M., Beck, N., Geisser, M., O’Leary, D., Giordani, B., \& Berent, S. (1988). Neuropsychological correlates of academic achievement of children with epilepsy. J Epilepsy, 1, 23-29.

Semrud-Clikeman, M. \& Wical, B. (1999). Components of attention in children with complex partial seizures with and without ADHD. Epilepsia, 40(2), 211-215. http://www.ncbi.nlm.nih. gov/pubmed/9952269

Sherman, E.M.S., Slick, D.J., \& Eyrl, K.L. (2006). Executive dysfunction is a significant predictor of poor quality of life in children with epilepsy. Epilepsia, 47(11), 1936-1942. https://doi.org/10. 1111/j.1528-1167.2006.00816.x

Shinnar, R.C., Shinnar, S., Cnaan, A., Clark, P., Dlugos, D., Hirtz, D.G., .. Glauser, T.A. (2017). Pretreatment behavior and subsequent medication effects in childhood absence epilepsy. Neurology, 89(16), 1698-1706. https://doi.org/10.1212/WNL. 0000000000004514

Slick, D., Lautzenhiser, A., Sherman, E., \& Eyrl, K. (2006). Frequency of scale elevations and factor structure of the Behavior Rating Inventory of Executive Function (BRIEF) in children and adolescents with intractable epilepsy. Child Neuropsychology, 12(3), 181-189. https://doi.org/10.1080/ 09297040600611320

Stoppa, E. \& Biancardi, A. (1997). Il test delle Campanelle modificato: una proposta per lo studio dell'attenzione in età evolutiva. Psichiatria Dell'Infanzia e Dell'Adolescenza, 64, 73-84.

Stuss, D.T. (2011). Functions of the frontal lobes: Relation to executive functions. Journal of the International Neuropsychological Society, 17(5), 759-765. https://doi.org/10.1017/S1355617711000695

Stuss, D.T. \& Benson, D.F. (1984). Neuropsychological studies of the frontal lobes. Psychological Bulletin, 95(1), 3-28. https://doi. org/10.1037/0033-2909.95.1.3

Tracy, J.I., Osipowicz, K., Spechler, P., Sharan, A., Skidmore, C., Doucet, G., \& Sperling, M.R. (2014). Functional connectivity evidence of cortico-cortico inhibition in temporal lobe epilepsy. Human Brain Mapping, 35(1), 353-366. https://doi.org/10. 1002/hbm.22181

Vlooswijk, M.C.G., Vaessen, M.J., Jansen, J.F.A., De Krom, M.C.F.T. M., Majoie, H.J.M., Hofman, P.A.M., ... Backes, W.H. (2011). Loss of network efficiency associated with cognitive decline in chronic epilepsy. Neurology, 77(10), 938-944. https://doi.org/10.1212/WNL.0b013e31822cfc2f

Waites, A.B., Briellmann, R.S., Saling, M.M., Abbott, D.F., \& Jackson, G.D. (2006). Functional connectivity networks are disrupted in left temporal lobe epilepsy. Annals of Neurology, 59(2), 335-343. https://doi.org/10.1002/ana.20733

Williams, J., Phillips, T., Griebel, M.L., Sharp, G.B., Lange, B., Edgar, T., \& Simpson, P. (2001). Factors Associated with Academic Achievement in Children with Controlled Epilepsy. Epilepsy and Behavior, 2(3), 217-223. https://doi.org/10.1006/ ebeh.2001.0166

Witt, J.A. \& Helmstaedter, C. (2012). Should cognition be screened in new-onset epilepsies? A study in 247 untreated patients. Journal of Neurology, 259(8), 1727-1731. https://doi.org/10. 1007/s00415-012-6526-2

Zhao, Q., Rathouz, P.J., Jones, J.E., Jackson, D.C., Hsu, D.A., Stafstrom, C.E., ... Hermann, B.P. (2015). Longitudinal trajectories of behavior problems and social competence in children with new onset epilepsy. Developmental Medicine and Child Neurology, 57(1), 37-44. https://doi.org/10.1111/dmen.12549 